\title{
Development and a Pilot Application Process of the Korean Psychological Autopsy Checklist for Adolescents
}

\author{
Mina Jeon ${ }^{1,2}$, Han Nah $\mathrm{Cho}^{3}$, Soo Young Bhang ${ }^{3,4} \bowtie$, Jun Won Hwang ${ }^{5}$, \\ Eun Jin Park ${ }^{3,6}$, and Yeon Jung Lee ${ }^{7}$ \\ ${ }^{1}$ Department of Psychiatry, Eulji Hospital, Seoul, Republic of Korea \\ 2Department of Psychology and Human Development, UCL Institute of Education, London, UK \\ ${ }^{3}$ Suicide and School Mental Health Institute, Hallym University, Anyang, Republic of Korea \\ ${ }^{4}$ Department of Psychiatry, Eulji University School of Medicine, Eulji Hospital, Seoul, Republic of Korea \\ ${ }^{5}$ Department of Psychiatry, Kangwon National University College of Medicine, Chuncheon, Republic of Korea \\ ${ }^{6}$ Department of Psychiatry, Inje University College of Medicine, Ilsan Paik Hospital, Goyang, Republic of Korea \\ ${ }^{7}$ Department of Psychiatry, Soonchunhyang University Seoul Hospital, Seoul, Republic of Korea
}

\begin{abstract}
Objective The aim of the study was to develop the Korean Psychological Autopsy Checklist for Adolescent (K-PAC-A) and conduct a pilot study.

Methods A number of steps were undertaken in the development of the K-PAC-A including literature reviews, consultations, and a pilot study. The Korean psychology autopsy checklist 2.0 (K-PAC 2.0) was carefully reviewed to adopt some domains and questions which can be applied to adolescents.

Results In addition to the adoption of some domains and questions from the K-PAC 2.0, some items were developed by considering the risk factors shown in the previous studies and cultural factors including family-based and school-based problems. A pilot study was conducted in collaboration with Eulji hospital, and Suicide and School Mental Health Institute of Hallym University and 5 cases of adolescent suicide victims were recruited. A final version of the K-PAC-A consists of three domains; a bereaved family (informants), a decedent, and psychological assessments.

Conclusion An adolescent psychological autopsy study using the K-PAC-A is expected to provide useful evidence for suicide prevention policies and intervention plans for Korean youths in the future.

Psychiatry Investig 2018;15(5):490-498
\end{abstract}

Key Words Psychological autopsy, Adolescent, Children, Suicide.

\section{INTRODUCTION}

Suicide is a result of complex interactions between various factors such as a mental illness, stress, a conflict with others, health problems and sociocultural factors. ${ }^{1,2}$ Therefore, it is essential to identify a cause of such factors comprehensively and a psychological autopsy is one way of assuming the cause of suicide risk factors by interviewing a bereaved family of a decedent or people who were close to a decedent. ${ }^{3}$

The first modern meaning of a psychological autopsy study

Received: October 5, 2017 Accepted: November 7, 2017

$\triangle$ Correspondence: Soo Young Bhang, MD, PhD, MPH

Department of Psychiatry, Eulji University School of Medicine, Eulji Hospital, 68 Hangeulbiseok-ro, Nowon-gu, Seoul 01830, Republic of Korea

Tel: +82-2-970-8303, Fax: +82-2-970-8429, E-mail: bsy1@eulji.ac.kr

(c) This is an Open Access article distributed under the terms of the Creative Commons Attribution Non-Commercial License (http://creativecommons.org/licenses/by$\mathrm{nc} / 4.0$ ) which permits unrestricted non-commercial use, distribution, and reproduction in any medium, provided the original work is properly cited. was conducted by Robins and his colleagues, interviewing bereaved families of 134 suicide victims between 1956 and $1957 .{ }^{4}$ Nonetheless, the term 'psychological autopsy' was firstly introduced by Schneidman and Farberow (1965) and their purpose of using the psychological autopsy was to give useful evidence to coroners if the mode of death was not clear. ${ }^{5}$ Later on, a first nationwide psychological autopsy study was implemented in Finland and this enabled the National Health Committee to classify the causes of suicide and develop evidence-based suicide prevention programs. ${ }^{6}$ The nationwide promotion of suicide prevention projects was successful in reducing the suicide rate from 30 per 100,000 population in 1990 to 16.7 per 100,000 population in $2008 .{ }^{6}$ From the 1990 s, the psychological autopsy has been widely spread to many other countries including western countries as well as Asian countries involving Taiwan, India, China and Hong Kong. And a systematic psychological autopsy study was emerged by 
conducting case-control studies using structured measurements. ${ }^{6}$

In South Korea, on the other hand, the first psychological autopsy study was conducted by the Korea Association for Suicide Prevention in 2009, in cooperation with the Mental Health Promotion Center and the National Police Agency. ${ }^{6}$ This study utilized a psychological autopsy measurement developed by Michael Phillips ${ }^{7}$ after translating it into Korean and interviewed seven cases of suicide victims. ${ }^{8}$ The Lifeline Korea carried out a second psychological autopsy study by developing a psychological autopsy measurement based on the Weisman's psychological autopsy guideline ${ }^{9}$ and materials from US Department Defense. ${ }^{10}$ As a result, ten psychological autopsy interviews were completed. ${ }^{11}$ However, it is difficult to make significant implications using the results of these studies since both studies involved a limited number of cases. Sea et al. ${ }^{12}$ conducted another psychological autopsy study between 2009 and 2011 and addressed this problem by completing 56 psychological autopsy interviews. This study compared a suicide group with a control group and found similar results shown in the previous studies that the suicide group showed significantly more mental illnesses and stress, and had an experience of suicide and self-harm attempts compared to the control group. ${ }^{1,2}$ The fourth psychological autopsy study was conducted in collaboration between Seoul Suicide Prevention Center and community mentor health centers by utilizing the measurement developed by the Korea Association for Suicide Prevention. ${ }^{13}$ This measurement was developed by considering a purpose of use and characteristics of each region in South Korea. And later on, Korea Psychological Autopsy Centre attempted to develop a standardized psychological autopsy measurement to clarify the causes of suicide more concisely. As a result, the Korean psychology autopsy checklist 2.0 (K-PAC 2.0) was developed in 2014 by reviewing other psychological autopsy measurements used in Korea and other countries. ${ }^{14}$ However, the K-PAC 2.0 is only applicable to adult decedents who are over 19 years old and each case should have been confirmed their suicidal death through a police investigation. ${ }^{15}$ Therefore, this measurement cannot be used to conduct a psychological autopsy for children and adolescents.

Nevertheless, a youth suicide rate in South Korea was 3.5 per 100,000 in 2002, which was increased to 6.5 in 2009 and decreased to 4.5 per 100,000 in $2014 .{ }^{16}$ And the percentages of juvenile deaths due to suicide increased from $18.8 \%$ in 2005 to $24.7 \%$ in 2014, leading the suicide as a first or second major cause of juvenile death every year. ${ }^{17}$ Despite these phenomena, only one adolescent suicide case was involved in the previous psychological autopsy study in South Korea. ${ }^{6}$ However, the study has a significant limitation as the adoles- cent psychological autopsy was conducted by using the measurement developed specifically for adults. Therefore, it is very likely that the study could not grasp important characteristics of youth such as school life and relationships with friends. In order to overcome this drawback, a development of psychological autopsy measurement for children and adolescents is necessary. Thus, the purpose of this study was to develop the Korea Psychological Autopsy Checklist for children and adolescents (K-PAC-A) and provide a standard guideline for the use of the K-PAC-A, thereby providing useful evidence which can contribute to a development of the national suicide prevention policy for Korean children and adolescents.

\section{METHODS}

A number of steps were undertaken in the development of the K-PAC-A as shown in Table 1. As a prior development work, seven studies were selected for a literature review of children and adolescent psychological autopsy study. And a general consultation for the adolescent psychology autopsy was sought by having a meeting with an American expert in the field of the adolescent psychological autopsy and by attending a K-PAC 2.0 workshop. In the next step, some domains and items which can be applied to adolescent suicide victims were extracted from the K-PAC 2.0 and some domains were developed by considering findings from previous studies and specific characteristics of Korean youths. After formulating a first draft of the K-PAC-A, one of the researchers received training by attending a psychological autopsy training program, organized by American Association of Suicidology (AAS). Therefore, a further modification has been done by reviewing the AAS measurement and feedbacks were obtained from some experts in the field of the psychological autopsy and suicide. After that, psychological autopsy interviews for 5 cases of adolescent suicide victims were conducted for a pilot study. At last, any problems or opinions raised during the pilot study were taken into account and a final questionnaire was developed.

\section{Prior development work-literature review of adolescent psychological autopsy}

In South Korea, only one adolescent psychological autopsy interview was carried out by using an adult psychological autopsy measurement. ${ }^{6}$ Therefore, child and adolescent psychological autopsy studies performed in other countries were reviewed. The previous studies were searched by using keywords such as 'psychological autopsy', 'adolescent', 'children', and 'suicide'. Among those, seven papers were selected based on a general description of the psychological autopsy studies 
Table 1. Steps undertaken in the development of the K-PAC-A

\begin{tabular}{lll}
\hline Step 1 & Prior development work & Literature review \\
Step 2 & Consultation for adolescent's psychological autopsy in general & K-PAC 2.0 workshop \\
& & Psychological autopsy experts from the USA \\
Step 3 & Domain classification and item generalization & Adopt some domains from the K-PAC 2.0 \\
& & Develop new domains by considering findings from previous \\
& studies and adolescents' characteristics \\
Step 4 & Consultation about a pilot questionnaire & Received feedbacks from some experts \\
& & Participated a psychological autopsy classification training \\
Step 5 & Pilot study & program in the USA \\
Step 6 & Final questionnaire & Interviewed 5 parents of adolescent suicide victims \\
\hline
\end{tabular}

K-PAC-A: Korean Psychological Autopsy Checklist for Adolescents, K-PAC 2.0: Korean Psychology Autopsy Checklist 2.0

and a validity of the results.

\section{Consultation on adolescent's psychological autopsy in general}

During the early stage of developing the psychological autopsy checklist for adolescents, an American expert who had an experience of developing and conducting adolescent psychological autopsy studies visited South Korea and gave advice on the development of adolescent psychological autopsy measurement. The researchers also participated in a psychological autopsy workshop held by the Korea Psychological Autopsy Center and received a consultation from experts in the field of the psychological autopsy and suicide in South Korea.

\section{Domains classification and item generalization}

The researchers reviewed the K-PAC 2.0 which was developed mainly for adults. Researchers carefully reviewed each domain and question in the K-PAC 2.0 and adopted some domains and items if it is suitable for adolescents and meets the characteristics of Korean youths. In addition, considering the findings and measurements used in the previous studies, some new domains and questions were developed.

\section{Consultation on the first draft of K-PAC-A}

A child and adolescent psychiatrist involved in this study attended a Psychological Autopsy Certification Training Program operated by AAS and learned the useful technics and accumulated know-how for a standardized adolescent psychological autopsy study. Moreover, four psychiatrists and one psychologist reviewed the first draft of K-PAC-A and provided feedback. The final draft of the K-PAC-A was developed by taking account of the AAS measurement, information received from the training and feedbacks from the experts.

\section{Pilot study}

The pilot study was approved by Eulji hospital Institutional Review Board (2015-07-013-001) and carried out in collaboration with Eulji hospital and Suicide and School Mental Health Institute, Hallym University. Researchers advertised this study to Korea Psychological Autopsy Center, Mental Health Center and Ministry of Education in order to recruit participants. Parents of youth decedents were contacted via telephone and interview places and schedules were discussed. The interviews were taken place at either a participant's home, community mental health centers, or clinic rooms in the mental health department of hospitals. One main interviewer and one interview assistant were involved in the interview and the interview usually took 3 hours in average. After two weeks from the interview, follow up calls were made to each participant.

\section{Final questionnaire}

Interviewers reported any concerns occurred during the interview and suggested improvements. After the problem analysis, a final questionnaire was developed through further modifications.

\section{RESULTS}

\section{Results from the literature review of adolescent psychological autopsy studies (Table 2)}

Selected studies were conducted in a number of countries including three regions in the USA; Kentucky, ${ }^{18}$ Pittsburg, ${ }^{19}$ and Utah, ${ }^{20,21}$ four regions in the UK; Northamptonshire, Berkshire, Buckinghamshire and Oxfordshire, ${ }^{22}$ Quebec in Cana$\mathrm{da},{ }^{23}$ and Flandre in Belgium. ${ }^{24}$

Overall, the previous studies revealed several risk factors associated with youth suicide (Table 2). First of all, it was found that many adolescent suicide victims suffered from mental illnesses such as affective disorders, drug and alcohol abuse disorders and personality disorders, ${ }^{18-24}$ but avoided 


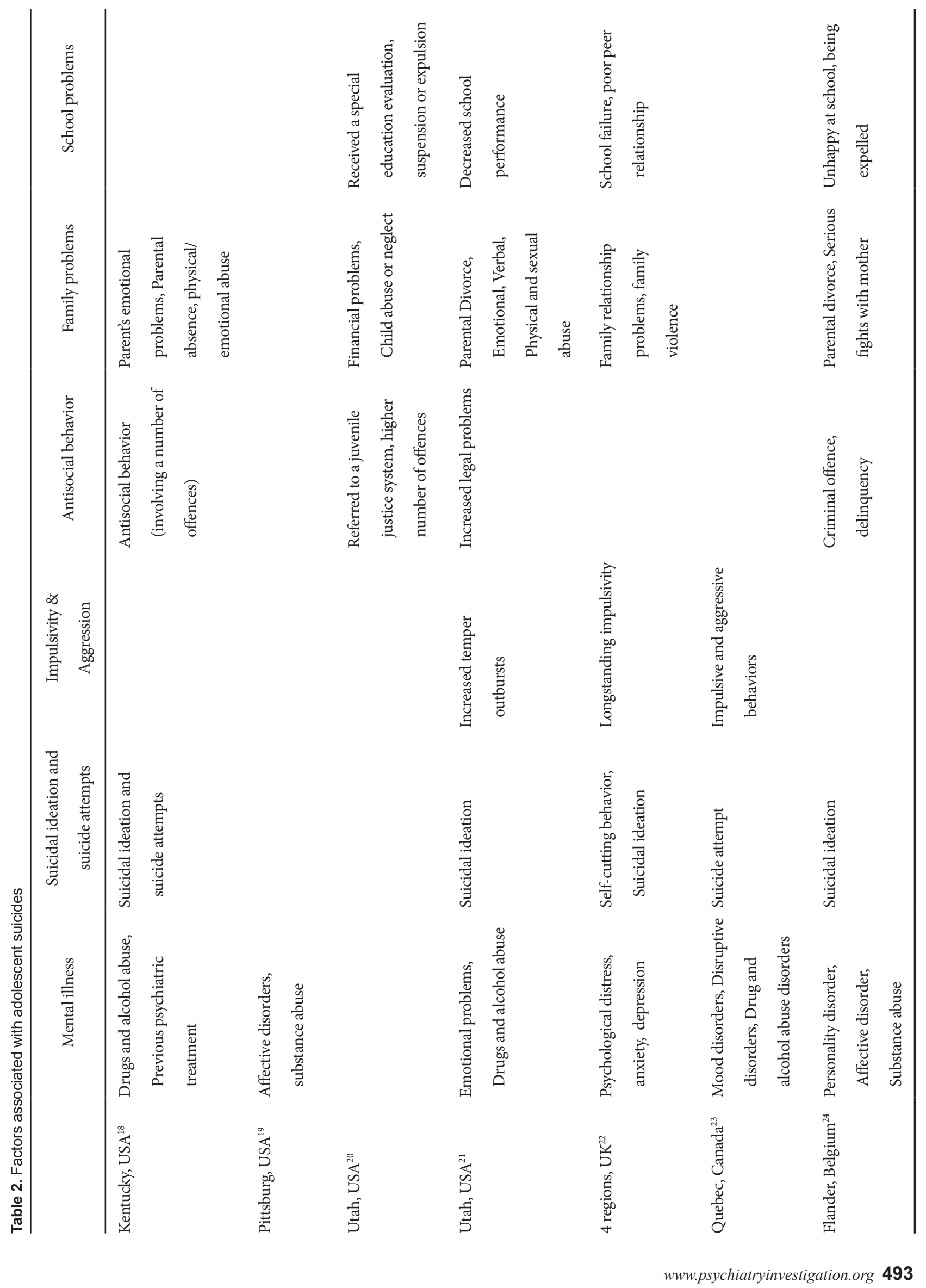


receiving appropriate treatment. ${ }^{20,21,24}$ The second characteristic of deceased adolescents is that they had an experience of suicidal ideation and suicide attempts before completing the suicide. ${ }^{18,21-24}$ Ribeiro and Joiner ${ }^{25}$ suggested that repetitive suicide attempts increase the risk of suicide by enhancing tolerance to pain and reducing the fear of death. And a high level of aggression and impulsivity were shown in deceased adolescents. ${ }^{21-23}$ They used to have anti-social behaviors such as criminal behaviors and juvenile delinquency. ${ }^{18,20,21,24}$ Based on this finding, it was assumed that some adolescent suicide victims who had the high level of aggression and impulsivity might commit suicide impulsively without any pre-planning of suicide. In addition to this, family-based and school-based problems were associated with adolescent suicide. The most frequently reported family problems were an experience of abuse and parental divorce ${ }^{18,20-22}$ while problems with peers, school maladjustment, and expulsion were reported as problems experienced at school. ${ }^{20,22,24}$

\section{Result of the domain classification and item generalization}

The researchers reviewed the K-PAC 2.0 and adopted some domains and items which meet the characteristics of children and adolescents. Among the adopted questions, further modifications were made by considering a number of vulnerable factors to youths. For instance, a category for a parent of deceased adolescents was subdivided into biological parents and stepparents since a parental divorce or a bereavement might exert a negative effect on psychological and emotional states of their children, thereby increasing the risk of suicide. In addition, questions asking the time of incidences and methods of manifesting self-harm behaviors and warning signs of suicide were subdivided and changed from an open question to a multiple choice question.

In the course of the review, some questions were developed by considering the cultural factors. First of all, some institutions which provide supports and intervention services to Korean youths such as Wee Centers and nationwide Youth Counseling and Welfare Centers were included in a multiple choice question asking if they have been to certain institutions due to their problematic behaviors. Another cultural factor which needs to be considered is a high attainment rate of university-level education in Korea. According to the OECD, the number of Koreans attained at university-level education was higher than the average of OECD nations and the attainment rate among 25-34-year-old Koreans has been increased from 37\% in 2000 to $66 \%$ in $2012 .{ }^{26}$ Along with this, academic stress was the most common stress among Korean adolescents compared to four other types of stresses such as stress related to appearance and parents ${ }^{27}$ and several studies pointed out that academic stress is highly associated with suicidal ideation. ${ }^{28,29}$ Therefore, questions asking for academic achievements and academic-related stress were included. In addition, according to a national survey conducted in 2016, 28,000 Korean adolescents reported their experiences of bullying. ${ }^{30}$ Although the number of adolescent bully-victims has been dramatically decreased compared to 321,000 victims in 2012, ${ }^{30}$ the researchers decided to take account of experiences of bullying and peer relationships of deceased adolescents as previous studies have shown that bullying is highly associated with suicidal ideation and attempts. ${ }^{31,32}$ Lastly, compared to other age groups, the highest number of Korean adolescents was categorized into risk groups of internet addiction and smartphone addiction in 2014, representing $12.5 \%$ and $29.2 \%$ respectively. ${ }^{33}$ And the main reason for using the Internet was found to be blogging or updating a personal homepage and chatting or using messengers, especially among female adolescents. ${ }^{34}$ Since this implies a high possibility of leaving notes or memos on their blogs or SNS before committing the suicide, a question asking for any postings on the SNS before committing suicide was added.

Furthermore, to diagnose mental health of deceased adolescents, the K-PAC 2.0 utilized a psychological measurement, Mini International Neuropsychiatric Interview (MINI). ${ }^{14}$ However, as the MINI is mainly developed to diagnose the adult's mental health, major adolescent mental illnesses such as attention deficit hyperactivity disorder (ADHD), conduct disorder (CD) and oppositional defiant disorder (ODD) are omitted and diagnostic criteria for several disorders including Dysthymia are different compared to diagnostic criteria for adolescents, for instance, in terms of a duration of illness. In addition, to the best knowledge of the researchers, MINI for children and Adolescents (mini-KID) has not been translated in Korean yet. For this reason, researchers decided to use Kiddie Schedule for Affective Disorders and SchizophreniaPresent and Lifetime (K-SADS-PL) instead of mini-KID.

And the researchers attempted to take account of a bereaved family's psychological and emotional states as well as their opinions towards the psychological autopsy interview. Therefore, the bereaved family's stage of mourning was assessed and any difficulties or supports they experienced during the interview were asked at the end of the interview. And information about bereaved family counseling and bereaved family meetings was given to them.

\section{Result of the consultation for the pilot questionnaire}

Advisory panels and researchers reviewed the psychological autopsy training materials provided by the American Association of Sociology (AAS) and developed the first draft 
of the K-PAC-A. The major difference between the psychological autopsy measurement developed by the AAS and the K-PAC-A was that the K-PAC-A mainly consists of questions about negative events such as psychiatric history and stress factors, whereas the AAS measurement includes many positive factors such as religious activities, social supports, and hobbies. Therefore, researchers suggested supplementing such positive questions in the K-PAC-A. In addition, the AAS assessed a variety of psychological characteristics of deceased adolescents including aggression, impulsivity, perfectionism and compulsive personality by using a psychological assessment instrument, suggesting that further discussion on the usefulness of such assessment is needed. Through all these processes, a final draft of the K-PAC-A was developed.

\section{Modification and development through the pilot study}

A pilot study was carried out using the final draft of the KPAC-A and participants were recruited in cooperation with related organizations including Korea Psychological Autopsy Center, Korea Suicide Prevention Centers and Community Mental Health Centers. As a result, 5 cases of adolescent suicide victims (three males and two females) were involved in the pilot study and one of the parents of each case participated in the adolescent psychological autopsy interview. The age range of five cases was between 15 and 19 years old (Mean age was 16.8 years old). After completing the psychological autopsy interview of each case, the draft of the KPAC-A was developed and modified simultaneously by considering the opinions of both interviewers and informants.

This paper only focused on the developmental process of the K-PAC-A since more data should be collected to analyse the data. The first case involved in the pilot study suffered from severe stress due to academic achievement failures. Therefore, questions about school grades or achievements and experience of school transition were supplemented. Moreover, the draft of the K-PAC-A revealed a limitation in identifying any significant events or changes happened to deceased adolescents just before committing the suicide. Thus, questions asking such factors were included. In the case of children and adolescents, a financial status of family and a family structure could affect their self-esteem. Therefore, a few financial questions and a family tree were supplemented. Lastly, a timeline was added to help an informant remembering the time of incidences more accurately.

In the case of a second psychological autopsy interview, the interview did not go smoothly as a parent told a whole story about their deceased child at the beginning of the interview when they were asked about possible causes of their child's suicide. The causes of suicide were asked twice at the beginning as well as at the end of the interview by reflecting the opinions of the advisors who wanted to see the changes in parents' insight during the interview. To overcome this problem, the question asking the cause of suicide at the beginning of the interview was removed and only asked at the end of the interview and questioned further if there were any changes in their opinions after the interview. In addition, an interviewer claimed the necessity of including a question about an experience of physical abuse as it could have caused tremendous stress to deceased adolescents. Furthermore, the parent showed a difficulty of remembering critical accidents the deceased adolescent experienced during the development. To enhance their memory, the question was transformed to multiple choice question by giving them examples of post-traumatic stress disorder (PTSD) which were included in the K-SADS-PL. At last, the parent tended to report the approximate time of events instead of remembering an accurate date of the incident, so researchers added a calendar to help interviewers and family members collecting accurate information.

Throughout the second and third interviews, there was a tendency that parents could not recognize or underestimate the psychopathology of their deceased children which makes an interviewer difficult to diagnose suicide victims' mental disorders such as depression and ADHD. To overcome this problem, researchers supplemented a depression scale and the Korean version of the ADHD Rating Scale (ARS).

From a fourth interview onwards, there was no need to add any additional items. The only thing amended after the fourth interview was an order of question according to developmental sequences and an order of psychological assessment to be carried out first by considering a flow of the interview. In general, the characteristics of each deceased adolescent involved in the pilot study were all different, enabling researchers to reflect various characteristics of adolescents in the process of revising and reviewing the K-PACA. Therefore, the researchers concluded that the reviewed K-PAC-A could be suitably used for adolescent psychological autopsy studies in South Korea.

\section{Final questionnaire}

A final version of the K-PAC-A consists of three domains; a bereaved family (informants), a decedent, and psychological assessment, which is the same structure as the K-PAC 2.0 (Table 3). However, there are a different number of sub-domains under the domains for decedents and psychological assessments, due to an elimination of non-applicable items and a development of some new sub-domains by considering specific characteristics of Korean youths. For instance, employment, financial status and military services, and marriage relationship have been eliminated within the domain for de- 
Table 3. Comparison of contents of the K-PAC 2.0 and the K-PAC-A

\begin{tabular}{|c|c|c|}
\hline & K-PAC 2.0 & K-PAC-A \\
\hline $\begin{array}{l}\text { Bereaved family } \\
\text { (Informants) }\end{array}$ & $\begin{array}{l}\text { 1. General information } \\
\text { 2. Responses and coping skills } \\
\text { 3. Psychological and Emotional states }\end{array}$ & $\begin{array}{l}\text { 1. General information } \\
\text { 2. Responses and coping skills } \\
\text { 3. Psychological and Emotional states }\end{array}$ \\
\hline Decedent & $\begin{array}{l}\text { 1. General information } \\
\text { 2. Suicidal behaviour and information about death } \\
\text { 3. Employment, Financial Status and Military Services } \\
\text { 4. Family and Marriage relationship } \\
\text { 5. Romantic relationship and Relationship with others } \\
\text { 6. Others } \\
\text { 7. Information related to Physical health (Decedent) } \\
\text { 8. Information related to Mental health (Family and friends) }\end{array}$ & $\begin{array}{l}\text { 1. General information } \\
\text { 2. Suicidal behaviour and information about death } \\
\text { 3. Family relationship } \\
\text { 4. Developmental history and any related history } \\
\text { 5. Life at school and relationship with peers and teachers } \\
\text { 6. Romantic relationship and Relationship with others } \\
\text { 7. Internet and game use } \\
\text { 8. Information related to Physical health (decedent) } \\
\text { 9. Information related to Mental health (family and friends) }\end{array}$ \\
\hline $\begin{array}{c}\text { Psychological } \\
\text { assessment }\end{array}$ & 1. MINI & $\begin{array}{l}\text { 1. K-SADS-PL } \\
\text { 2. Depression Scale } \\
\text { 3. K-ARS }\end{array}$ \\
\hline
\end{tabular}

MINI: Mini International Neuropsychiatric Interview, K-SADS-PL: Kiddie Schedule for Affective Disorders and Schizophrenia-Present and Lifetime, K-ARS: Korean ADHD Rating Scale

cedent while developmental history and any related histories, life at school and relationship with peers and teachers, and the Internet and game use have been added.

\section{DISCUSSION}

A youth suicide can be a more tragic experience for their parents, teachers, and peers as they might feel guilty of not preventing their suicide and more likely to cause a trauma and psychological problems. ${ }^{35,36}$ To prevent the youth suicide more effectively, an adolescent psychological autopsy study should be carried out to identify possible causes and risk factors of youth suicides. Therefore, this study developed the Korean Psychological Autopsy Checklist for Adolescents (KPAC-A) through several stages involving a literature review and consultations.

The K-PAC-A is a measurement which possibly records both quantitative and qualitative information and it involves two types of questions; one of which is for family members to answer the questions and the other one is for interviewers to assess a bereaved family's stage of mourning and to evaluate the reliability of information since the bereaved family might tend to avoid answering sensitive questions in a negative way. Therefore, reliable information can be obtained from informants. In addition, the K-PAC-A is recommended to be conducted at least six months after the death, allowing an enough period of mourning, as previous studies also contacted the bereaved family at least 3-4 weeks after the death. ${ }^{19,20,21,24}$ Consideration of psychological and emotional states of the bereaved family at the beginning of the interview can lead to a formation of rapport between interviewers and informants as it conveys a meaning that the interviewer takes care of a psychological well-being of the bereaved family.

Unlike the previous studies which utilized different measurements, the K-PAC-A was developed by adopting several items from the K-PAC 2.0. Therefore, although results of previous studies cannot be compared directly, a direct comparison of the results from the K-PAC-A and the K-PAC 2.0 is possible. This might give a new insight into the field of suicide research by comparing characteristics of adolescent suicide and adult suicide. Moreover, there are a number of implications for a youth suicide prevention and treatment. For the suicide prevention, an accumulation of official data on causes and risk factors of youth suicide at home or schools will contribute to an establishment of evidence-based policies and action plans for coping strategies of youth suicides. As a consequence, family members, teachers, and counselors can improve their suicide prevention and coping skills and this will reduce the adolescent suicide rates. Regarding the treatment, the results of adolescent psychological autopsy studies will allow a development of schemes for trauma resolution and healthy mourning process for family members, teachers, and friends of deceased adolescents by considering their current mourning stages and psychological or emotional states. Through this, their feeling of guilt and negative thinking can be resolved.

This study has several limitations that have to be considered in a follow-up study. First, there is a barrier in a participant recruitment for a psychological autopsy study as there are a number of laws related to a bereaved family in South Korea, for example, strengthened personal information protection acts, the principle of protection and self-determination of a 
bereaved family and the principle of respecting a bereaved family's opinion first if there is a conflict between schools and bereaved families. Moreover, the recruitment of adolescent suicide victims for a psychological autopsy study is harder than adult suicide cases. The number of deceased adolescents participating in the previous studies was only ranged between 19 and $55 . .^{18-24}$ This can be simply because the actual number of youth suicides is less than adult suicides. Therefore, it is harder to find participants for adolescent psychological autopsy studies. Another possible reason for the low rate of participation is because of a tendency that family members do not want to disclose their children's suicide. ${ }^{6}$ The previous studies reported that only $47-83 \%$ of bereaved families agreed to take part in the psychological autopsy interview. ${ }^{18-24}$ Such low rate of consent from bereaved families supports this point of view. Therefore, a public advertisement and cooperation with related organizations are required to secure enough cases for the children and adolescent psychological autopsy study.

The K-PAC-A was developed mainly for a bereaved family of youth decedents and an eligibility of participation as an informant is limited to parents, siblings (over 19 years old) and grandparents. Furthermore, the pilot study of the K-PAC-A was conducted to only one of the family members of deceased adolescents. Therefore, it is difficult to confirm the reliability of information and hard to identify biased information. The previous studies obtained additional information from a second and third informant if a parent gives a consent ${ }^{18-21,24}$ and have shown that information provided by close friends of deceased adolescents were different from family members and tended to be less biased. ${ }^{18,20,21,24}$ Therefore, it is necessary to develop another psychological autopsy measurement which is suitable for friends or siblings of deceased adolescents who are under 19 years of age, as reported in the previous study. ${ }^{25}$ In addition, considering the characteristics of adolescents who spend most of their time at school, a psychological autopsy checklist for teachers should be developed to identify the characteristics of children and adolescents at school.

A major limitation of this study is that the number of cases involved in the pilot study was small. Therefore, if more number of cases for the K-PAC-A is obtained over time, the validity and reliability of the K-PAC-A should be verified.

Lastly, the K-PAC-A is a measurement which should be used by interviewers who have a number of experiences of carrying out clinical interviews and able to diagnose children's psychopathology. Therefore, clear criteria and a psychological autopsy training program for psychological autopsy interviewers should be developed. If a certificate or a qualification is provided based on the experiences of carrying out a psy- chological autopsy interview and completing a psychological autopsy training course like the American Suicide Association (ASS), this can be used as a proof of their professionalism and secure a number of skilled psychological autopsy interviewers.

The K-PAC-A is developed by taking several steps from literature reviews to conducting a pilot study. The initiation of adolescent psychological autopsy studies using the K-PACA will provide useful evidence for a formation of youth suicide prevention policies and intervention plans in the future. However, a further study is needed to verify the validity and reliability of the K-PAC-A with a large sample size. And the K-PAC-A developed in 2015 should be reviewed and modified once in every three years with consideration of cultural and historical changes.

\section{Acknowledgments}

This study was supported by a grant of the Ministry of Education, Republic of Korea (H20150274).

We would like to show our gratitude to our colleagues, Hyun Ju Hong from Hallym University, Suicide and School Mental Health Institute and Yong-sil Kweon from The Catholic University of Korea College of Medicine for their assistance throughout the study.

We also thank Douglas Gray, a professor of psychiatry at the university of Utah who provided his own expertise that assisted our research, and Hyunsoo Kim from Department of Psychiatry at Myeongji University, Jongwoo Paik from Department of Psychiatry at Kyeong Hee University, Seon Gyu Ko from Korea Psychological Autopsy Center, Jongik Park from Department of Psychiatry at Kangwon University and Seonju Kim from Hallym University, Suicide and School Mental Health Institute for comments that greatly improved the K-PAC-A.

\section{REFERENCES}

1. Agerbo E, Nordentoft M, Mortensen PB. Familial, psychiatric and socioeconomic risk factors for suicide in young people: nested case-control study. BMJ 2002;325:74.

2. Commonwealth of Australia (2005). Suicide-Risk Factors and Warning Signs. Available at: http://www.responseability.org/data/assets/pdf_ file/0015/4803/Suicide-Risk-Factors-and-Warning-Signs.pdf. Accessed June 1, 2017.

3. Jae YM. Suicide and psychiatric disorder. J Korean Soc Biol Ther Psychiatry 2004;10:3-10.

4. Robins E, Murphy GE, Wilkinson RH, Gassner S, Kayes J. Some clinical considerations in the prevention of suicide based on a study of 134 successful suicides. Am J Public Health Nations Health 1959;9:888-899.

5. Shneidman ES, Farbrverow NL. The Los Angeles suicide prevention center: a demonstration of public health feasibilities. Am J Public Health 1965;55:21-26.

6. Korean Association for Suicide Prevention. Psychological Autopsy of Suicide and Construction of the Case Management Service for Suicide Attempter. Sejong: Ministry for Health and Welfare; 2009.

7. Phillips MR, Yang G, Zhang Y, Wang L, Ji H, Zhou M. Risk factors for suicide in China: a national case-control psychological autopsy study. Lancet 2002;360:1728-1736.

8. Na KS, Paik JW, Yun MK, Kim HS. Psychological autopsy: review and considerations for future directions in Korea. J Korean Neuropsychiatr Assoc 2015;54:40-48.

9. Weisman AD. The Realization of Death: A Guide for the Psychological Autopsy. New York: Jason Aronson; 1974. 
10. United States Department of the Army. Suicide Prevention and Psychological Autopsy. Washington, DC: United States Department of the Army. Available at:http://timemilitary.files.wordpress.com/2013/03/dapamphlet-600-242.pdf. Accessed June 1, 2017.

11. Lifeline Korea. Study Based on Psychological Autopsy of the Suicide and Postvention Approaches. Seoul: Lifeline Korea; 2010.

12. Sea JH, Lee CH, Kim KI, Kim SH. Characteristics of Korean suicide: a case-control psychological autopsy study. Korean J Psychol Gen 2012;31: 323-344.

13. Lee GS, Choi MJ, Kim SJ, Park JY, Lee MS, Seo JH, et al. The semi-psychological autopsy study of suicides. Ment Health 2012;3:18-24.

14. Korean Psychological Autopsy Center. Korea-Psychological Autopsy Checklist 2.0; K-PAC 2.0. Seoul: Korean Psychological Autopsy Center; 2014.

15. Korean Psychological Autopsy Center. Korea-Psychological Autopsy Checklist 2.0 Guideline. Seoul: Korean Psychological Autopsy Center; 2014.

16. Statistics Korea. 2013 Youth Statistics. Seoul: Statistics Korea; 2014.

17. Korea Centers for Disease Control and Prevention. The Survey of Children and Adolescents' Mental Health in 2015. ChungJu: Korea Centers for Disease Control and Prevention; 2015.

18. Shafli M, Carrigan S, Whittinghill JR, Derrick A. Psychological autopsy of completed suicide in children and adolescents. Am J Psychiatry 1985; 142:1061-1064.

19. Brent DA, Perper JA, Goldstein CE, Kolko DJ, Allan MJ, Allman CJ, et al. Risk factors for adolescent suicide. A comparison of adolescent suicide victims with suicidal inpatients. Arch Gen Psychiatry 1988;25:581588.

20. Moskos M, Olson L, Halbern S, Keller T, Gray D. Utah Youth Suicide Study: Psychological Autopsy. Suicide Life Threat Behav 2005;35:536546.

21. Gray D, Keller T, Haggard L, Rolfs B, Achilles J, Tate D, et al. Utah youth suicide study: preliminary results. Utah's Health 1998;5:11-17.

22. Renaud J, Berlim, MT, McGirr A, Tousignant M, Turecki G. Current psychiatric morbidity, aggression/impulsivity, and personality dimensions in child and adolescent suicide: a case-control study. J Affect Disord 2008;105:221-228.

23. Fortune S, Stewart A, Yadav V, Hawton K. Suicide in adolescents: using life charts to understand the suicidal process. J Affect Disord 2007;100:
199-210.

24. Portzky G, Audenaert K, van Heeringen K. Psychosocial and psychiatric factors associated with adolescent suicide: a case-control psychological autopsy study. J Adolesc 2009;32:849-862.

25. Ribeiro JD, Joiner TE. The interpersonal-psychological theory of suicidal behavior: current status and future directions. J Clin Psychol 2009;65: 1291-1299.

26. OECD. Education at a Glance 2014: OECD Indicators. Paris: OECD publishing. Available at: https://www.oecd.org/edu/Education-at-aGlance-2014.pdf. Accessed June 1, 2017.

27. Lee KB, Jung W, Youm Y. A Multilevel Analysis of the Effect of Household Income Equality in Classes on Adolescent Stresses in South Korea. Paper presented at the annual meeting of the American Sociological Association Annual Meeting, Sheraton Boston and the Boston Marriott Copley Place; Boston, MA; 2008. Available at: http://citation.allacademic.com/meta/p243139_index.html. Accessed June 1, 2017.

28. Juon H, Nam JJ, Ensminger ME. Epidemiology of suicidal behavior among Korean adolescents. J Child Psychol Psychiatr Allied Discipline 1994;35:663-676.

29. Zong S. A study on adolescent suicide ideation in South Korea. Procedia Soc Behav Sci 2015;174:1949-1956.

30. Ministry of Education. A Second Field Survey on School Violence in 2016. Seoul: Ministry of Education; 2016.

31. Espelage DL, Holt MK. Suicidal ideation and school bullying experiences after controlling for depression and delinquency. J Adolesc Health 2013;53(1 Suppl):S27-S31.

32. Kim YS, Koh YJ, Leventhal B. School bullying and suicidal risk in Korean middle school students. Pediatrics 2005;115:357-363.

33. Ministry of Science, ICT and Future Planning. 2014 Internet Addition Survey. Seoul: Ministry of Science, ICT and Future Planning; 2015.

34. Heo J, Oh J, Subramanian SV, Kim Y, Kawachi I. Addictive internet use among Korean adolescents: a national survey. PLoS One 2014;9:e87819.

35. Lindqvist $\mathrm{P}$, Johansson L, Karlsson U. In the aftermath of teenage suicide: a qualitative study of the psychosocial consequences for the surviving family members. BMC Psychiatry 2008;8:26.

36. Brent DA, Perper J, Moritz G, Allman C, Friend A, Schweers J, et al. Psychiatric effects of exposure to suicide among the friends and acquaintances of adolescent suicide victims. J Am Acad Child Adolesc Psychiatry 1992;31:629-639. 